\title{
INTRACELLULAR GROWTH OF SOME VIRUSES OF THE POX GROUP. AN ELECTRON MICROSCOPIC STUDY OF INFECTED CHICK CHORIONIC CELLS
}

\author{
By T. H. FLEWETT \\ Department of Bacteriology, University of Leeds
}

(With Plates 9-13)

\begin{abstract}
Morgan, Ellison, Rose \& Moore (1954) described, in sections of cells infected with vaccinia and fowl-pox virus, bodies larger and less dense than the familiar infective elementary body form. They interpreted these structures as the vegetative form or one of the vegetative forms of the virus, a stage in the formation of new virus within the cell. They observed that in many cases these forms, which were distinguishable by being oval in section, and by possessing a thin surface membrane and an eccentric nucleus-like body, were embedded in finely granular or homogeneous material quite distinct from the rest of the cytoplasm. Since their observations were based on material fixed $48 \mathrm{hr}$. after infection in the case of vaccinia, and 3-5 days after infection in the case of fowl-pox, no sequence of events in the formation of these structures could be firmly established.

Intracellular forms differing from the familiar elementary body have also been described by Morgan et al. for herpes simplex virus and by Reissig \& Melnick (1955) for herpes B virus in sections of infected tissue culture cells.

This paper describes an attempt to gain direct information about the changes taking place during the first few hours of infection. Information about the duration of the 'eclipse phase' and time of first appearance of new infective virus is already available from the paper by Anderson (1954).
\end{abstract}

\section{MATERIALS AND METHODS}

\section{Virus strains}

(1) Vaccinia. The Lister Institute strain of vaccinia virus was used. After two passages on the chorio-allantoic membrane, a suspension was prepared by Craigie's (1932) method. The final suspension was derived from the third rabbit passage, and was purified by five cycles of differential centrifugation. It was prepared for inoculation on to the chorio-allantoic membrane by resuspending it in a mixture of Hartley's broth (1 part) and Tyrode's solution (2 parts). The broth, which was added in the vain hope of preventing the autoagglutination of the virus particles, was centrifuged at $25,000 \mathrm{~g}$ for $1 \mathrm{hr}$. before use. (Distilled water or very dilute buffer could not be used for fear of damaging the chorionic cells by the osmotic effect of a hypotonic inoculum.) Phase microscopy of the suspension showed that most of the elementary bodies had aggregated into clumps of 20-100, though there were still many single bodies to be seen. Electron microscopy of these vaccinial 
suspensions showed that there were no particles larger than $20 \mathrm{~m} \mu$ present other than the familiar brick-shaped bodies characteristic of air-dried pox viruses, and that there was very little non-particulate material associated with them. This observation eliminates the possibility of cells taking up by phagocytic action fragments of cellular debris which might subsequently be confused with unfamiliar forms of intracellular virus. The preparation showed an egg infectivity titre of $10^{8}$ infective particles $/ \mathrm{ml}$. In view of the observed aggregation, this probably represents a small fraction of the total infective virus present.

(2) Myxomatosis virus was kindly supplied by $\mathrm{Dr} \mathrm{C}$. H. Andrewes as a frozendried emulsion of infected rabbit skin. It was given two passages on chorioallantoic membranes; membranes of the second passage were ground in a mortar with Pyrex powder and broth. (Anderson's 1954 paper had not then appeared.) After centrifugation at $3500 \mathrm{~g}$ for $10 \mathrm{~min}$. the supernatant was taken for use.

(3) Ectromelia virus. This virus was isolated at the National Institute for Medical Research in 1951. Mice were infected by injection into the footpad. The liver of a moribund mouse was ground up with Pyrex powder and broth. After centrifugation at $3500 \mathrm{~g}$ for $10 \mathrm{~min}$. the supernatant was used to infect chorio-allantoic membranes.

(4) Fowl-pox. One strain was kindly supplied by the Ministry of Agriculture Veterinary Laboratories, Weybridge, Surrey; the other was that used by Dr Morgan and his colleagues, who kindly sent it to me.

These viruses were propagated on chorio-allantoic membranes; inocula were prepared as in the case of myxomatosis virus.

Chorio-allantoic membranes of White Leghorn eggs were 'dropped' on the 11th day after incubation and inoculated on the following day. The interval was to enable the chorionic cells to recover from the trauma inflicted in making the artificial air sac.

Egg membranes and rabbit skin were embedded and sections cut according to the method described by Eaves \& Flewett (1954). An EMU $2 \mathrm{C}$ electron microscope equipped with a 70 or $200 \mu$ objective aperture was used. In some cases gold sol particles were deposited on the sections before microscopy to make focusing easier (Flewett \& Tymms, 1956).

Virus preparations were titrated by counting pocks produced on chorio-allantoic membranes $48 \mathrm{hr}$. after infection in the case of vaccinia and myxomatosis and $72 \mathrm{hr}$. in the case of fowl-pox and electromelia viruses. Three eggs were used to each 10-fold dilution. Eggs were incubated at $38^{\circ} \mathrm{C}$. before inoculation and $35^{\circ} \mathrm{C}$. after inoculation.

\section{RESULTS}

\section{(1) Vaccinia}

Most of the observations were made with vaccinia virus, because purified suspensions of the elementary bodies are so easy to prepare.

Chorio-allantoic membranes were inoculated with $0.1 \mathrm{ml}$. of a suspension of washed vaccinia virus in broth-Tyrode solution as described above. Pieces of membrane were removed at intervals after infection of $\frac{1}{2}, 1,1 \frac{1}{2}, 2,3,4,6,8,10,12$, 
18 and $24 \mathrm{hr}$. They were fixed in situ for $15 \mathrm{~min}$. by flooding with $2 \%$ osmic tetroxide solution; the pieces then cut out were fixed for a further $90 \mathrm{~min}$. in the same solution before dehydrating in ethanol and embedding in methacrylate.

No virus, other than an occasional elementary body lying free or on the cell surface, could be found before $4 \mathrm{hr}$. In the sections taken from membranes $4 \mathrm{hr}$. after infection, virus bodies, singly or sometimes in clumps, could be seen on and just beneath the cell surface (Pl. 9a,b). These particles were very dense, and though sections were cut as thin as possible and photographed with the greatest care, little internal structure could be seen. Some, however, did appear to be hollow, resembling the doughnut form described by Banfield, Bunting, Strauss \& Melnick (1951). Such virus particles were seen indenting the cell membrane, but no evidence was obtained as to how they got through.

In the same sections sites of vegetative growth were found in the depths of the chorionic cells. These appeared as areas of fairly homogeneous or finely granular material; embedded in them were oval bodies, bounded by a single membrane, frequently showing an eccentric 'nucleoid', exactly as described by Morgan et al. (1954). Some of these oval bodies appeared incomplete in outline (Pls. 10-12). The granular material in which these structures were embedded appeared to consist of fine filaments 100-200 A. long and about $50 \mathrm{~A}$. diameter, seen against a homogeneous fairly electron-transparent background (Pl. 12). These areas were surrounded by rings of mitochondria; the density of mitochrondria in their vicinity was much greater than in the rest of the cytoplasm, though the distribution of the other cytoplasmic components appeared to be unaffected.

These areas of early virus growth were difficult to detect on the fluorescent screen of the microscope, and were found only after prolonged searching. They then appeared as featureless areas surrounded by mitochondria.

No areas of multiplication could be found in the $6 \mathrm{hr}$. sections. One seen at $8 \mathrm{hr}$. showed more numerous immature forms and a lesser concentration of mitochondria.

Ten hours after infection, the appearance was like that at $8 \mathrm{hr}$., but among the immature forms one or two were found resembling in structure the mature virus bodies described in fowl-pox inclusions (Eaves \& Flewett, 1955), having a larger nucleus-like structure, central instead of eccentric, and possessing a cortex of appreciable thickness instead of a thin surface membrane. At this stage the finely granular material in which the virus particles were embedded was still present; but it appeared more diffuse and less clearly demarcated from the cytoplasm; and mitochondria, though still numerous in the area, did not form the conspicuous ring that was seen in the $4 \mathrm{hr}$. sections. Virus particles were not seen on the surface of cells at $10 \mathrm{hr}$. (Pl. 13).

At 18 and $24 \mathrm{hr}$. after infection, numerous virus particles of both kinds could be found within many cells without difficulty, presenting the kind of picture already well described by Morgan et al. In some cells, two separate groups of virus particles were seen : one consisting almost entirely of immature, the other of mature formspossibly analogous to the double infections sometimes seen in malarial blood, where one erythrocyte may contain two parasites at different stages of development. 
This sequence of events-inoculum persisting on the surface and just beneath the cell surface, the appearance of immature forms $4 \mathrm{hr}$. after inoculation, and the appearance of morphologically mature virus $10 \mathrm{hr}$. after infection-corresponds with the results obtained by Anderson (1954), whose time sequence of infection was exactly the same; he found that his inoculum disappeared over a period of 8-10 hr.; that the virus went into an 'eclipse' phase; and that new infective virus reappeared after $10 \mathrm{hr}$.

\section{(2) Other pox viruses}

Fowl-pox. (Weybridge strain used by Eaves \& Flewett, 1954.) Sections were examined from chorio-allantoic membranes infected $72 \mathrm{hr}$. previously with fowlpox virus. The virus occurred in two ways: first, as small groups of particles resembling the immature forms of vaccinia virus described above, associated sometimes with the granular material; secondly, sometimes within the same cell as the first kind, as aggregates of virus particles of the mature type resembling those described by Eaves \& Flewett in membranes 5 days after inoculation, though usually somewhat smaller.

It seemed desirable to make certain whether the first kind or the second kind of virus lesion represented the classical inclusion or Bollinger body. Two hens were therefore infected with the Weybridge strain of virus. Some feathers were plucked from both sides of their breasts, and a suspension of virus was rubbed into the follicles on one side, the method of inoculation used by Woodruffe \& Goodpasture (1929), who used it in preparing isolated inclusion bodies. The follicles on the other side were left uninoculated for comparison. One hen was killed after 5 days and the other after 10 days. The infected follicles were dissected out and cut into small pieces which were fixed and embedded in methacrylate. Sections were cut for ordinary microscopy. The follicle epithelium 10 days after infection had almost completely disintegrated, but that taken 5 days after infection, when the swelling of the follicles had reached its limit, contained numerous inclusion bodies as seen by the light microscope. These inclusion bodies, as seen by electron microscopy, all had a structure similar to those previously described by Eaves \& Flewett, though they were more irregular in shape, and the alignment of the long axes of the virus bodies was not so consistently parallel with the inclusion body's surface. Some of them contained in their centres the dense amorphous material previously found in inclusions in chorionic cells, and electron-dense granular material was seen between the virus bodies. These virus bodies were always of mature type. Virus of the immature type was very scanty and often could not be found at all.

Myxomatosis. Dropped chorio-allantoic membranes were inoculated with a dose sufficient to produce semi-confluent lesions after $72 \mathrm{hr}$. incubation. Pieces of chorio-allantoic membrane were fixed and embedded at this stage. Dr C. H. Andrewes kindly allowed me to take pieces of skin from the back and eyelid of a rabbit suffering from myxomatosis which was killed when it was moribund.

In the egg material, both vegetative and mature types of virus were found together in infected cells. Nothing sufficiently well defined to be termed an inclusion body was seen either by phase-contrast or electron microscopy. In spite 
of the naked-eye evidence of confluent pocks, virus was remarkably hard to find in sections of egg membranes.

Unstained sections of rabbit skin were examined by phase-contrast microseopy. Very many of the cells in the deeper layers of epithelium and also in the hair follicles were seen to be swollen and were packed with minute granules. Some looked hydropic. Electron microscopy showed that nearly every cell, in the prickle and basal cell layers, was packed with electron-dense virus particles, many of which appeared to have hollow centres similar to those described by Banfield et al. (1951) in sections of molluscum contagiosum lesions. Nuclei contained no virus particles but were often displaced to one side of the cell. A few small mitochondria were scattered among the virus bodies; they were usually slightly larger, up to $0 \cdot 4 \mu$ long, oval in section, and easily recognizable by their double internal membranes.

Ectromelia. Sections of chorio-allantoic membrane were examined. The tissue was fixed $72 \mathrm{hr}$. after infection with a dose of virus which produced semi-confluent pocks in this time. Both immature and mature-type particles were seen. The structure of the mature-type particles was not clearly defined in the few sections examined; but the immature forms were often very clearly defined and were sometimes larger than those of the other viruses investigated (Pl. $9 c)$. The eccentric nucleoids were often surrounded by an electron-transparent 'halo'.

Round or homogeneous structures were sometimes seen in infected cells, rather like some of the inclusion bodies described by Gaylord \& Melnick (1953). Their occurrence was erratic and their relationship with virus particles was uncertain. Since only a few sections of this material were examined, no conclusion will be drawn from them here.

\section{DISCUSSION}

These results confirm the observations of Morgan et al. (1954), that viruses of the pox group go through a phase within the cell when their structure differs from that of the mature infectious form. The time-infectivity curves of vaccinia virus growing on the chorio-allantoic membrane have been very neatly worked out by Anderson, and correspond very closely with the morphological changes described here. The correspondence was the more pleasing in that most of the results described here were obtained before Anderson's paper was available in this country. $\mathrm{He}$ found that $4 \mathrm{hr}$. after inoculation much of the original inoculum remained on the surface of the membrane (Pl. 9a); but that most of it had entered the membrane and passed into the 'eclipse' phase, from which it could not be recovered as infectious virus. It seems reasonable to compare this virus in eclipse with the intracellular forms designated in this paper as 'immature' (Pls. 10-12). According to Anderson, new infective virus first appeared $10 \mathrm{hr}$. after infection; in the experiments described here mature-type virus bodies first appeared among the immature forms at this time.

There is thus some evidence to suggest that the immature form is non-infective or of low infectivity, and that the mature form is of greater infectivity.

The classical experiments of Woodruffe \& Goodpasture (1929) showed that 
fowl-pox inclusion bodies are infective. The observation described here, that the virus bodies in fowl-pox inclusions are of the mature type, again suggests that it is this type of virus that is infective. The more irregular shape of the inclusions in the cells of the swollen feather follicle may be determined, at any rate in part, by mechanical stresses present in skin which do not exist in the dropped chorioallantoic membrane. Otherwise in their structure they so resemble those already described in the egg membrane that it has not been thought worth while to illustrate them here.

It was necessary that the identity of the classical Bollinger body with the aggregates of mature particles should be established because the question of infectivity arose. But with the application of electron microscopy the term 'inclusion body' rather loses its familiar meaning; it might now be reasonably applied to any localized intracellular manifestation of virus activity. Thus one might now say that the fowl-pox virus produces two kinds of inclusion: one, early in infection, the finely granular material with immature forms embedded in it; and the secondlate in the course of infection-the aggregation of mature infective virus which can be seen by light microscopy. The first kind is probably produced by all the pox viruses and the second only by some.

It had been hoped that electron microscopic examination of intracellular pox viruses would show clearly how they multiply; but the results have been disappointing. Stages in the transformation of the infective form into the non-infective immature form have not been found. Some of the immature forms appeared damaged or incomplete. This might be due to failure of fixation. But irrespective of fixation, such an incomplete spheroid may appear as the result of a cutting artifact, such as was seen in a section through a polymorphonuclear leucocyte encountered in the malarial blood of a monkey. It contained numerous granules about $0 \cdot 15-0 \cdot 25 \mu$ in diameter, which appeared oval. The section was marked by two minor irregularities in the knife edge. Here, some of the granules looked rather like the incomplete immature forms illustrated in Pls. 10 and 11 and also by Morgan et al.

The word 'incomplete' is used in this paper in a morphological sense only.

\section{SUMMARY}

Sections of chorio-allantoic membranes fixed at intervals after infection with large doses of vaccinia virus showed almost homogeneous areas appearing in the cytoplasm after $4 \mathrm{hr}$.; these areas contained immature forms of virus which had a thin surface membrane and an eccentric 'nucleoid', and were surrounded by mitochondria. Mature forms of virus, having a larger central nucleus-like structure and a thicker cortex, were first found in areas of virus growth $10 \mathrm{hr}$. after inoculation. Similar immature and mature forms were found in cells infected with fowl-pox, myxomatosis and ectromelia viruses. It is concluded that the immature forms are of low infectivity or not infective.

I am very grateful to Dr C. H. Andrewes, Dr F. B. Bang and Prof. C. L. Oakley for reading the manuscript and for helpful comments and advice. 


\section{REFERENCES}

Anderson, S. G. (1954). The growth curve of vaccinia virus on the chorioallantois. Aust. J. exp. Biol. Med. Sci. 32, 633.

Banfield, W. G., Bunting, H., Strauss, M. \& Melnick, J. L. (1951). Electron micrographs of thin sections of molluscum contagiosum. Proc. Soc. exp. Biol., N.Y., 77, 843.

Craigre, J. (1932). The nature of the flocculation reaction and observations on the elementary bodies of vaccinia. Brit. J. exp. Path. 13, 259.

Eaves, G. \& Flewett, T. H. (1954). Cutting of sections for electron microscopy with a modified 'Cambridge' rocking microtome. Exp. Cell Res. 6, 155.

Eaves, G. \& FlEWETT, T. H. (1955). The structure of fowl pox inclusions (Bollinger bodies). J. Hyg., Camb., 53, 102.

FlewetT, T. H. \& Tymms, P. (1956). Use of gold sols as an aid to focussing in highresolution electron microscopy. Nature, Lond., 177, 98.

Gaylord, W. H. \& Melnick, J. L. (1953). Intracellular forms of pox viruses as shown by the electron microscope. J. exp. Med. 98, 157.

Morgan, C., Ellison, S. A., Rose, H. M. \& Moore, D. H. (1954). Structure and development of viruses observed in the electron microscope. I. Herpes simplex virus. J. exp. Med. 100, 195. II. Vaccinia and fowl-pox viruses. J. exp. Med. 100, 301.

Reissig, M. \& MeLnick, J. L. (1955). The cellular changes produced in tissue cultures by herpes virus B correlated with the concurrent multiplication of the virus. J. exp. Med.101, 341.

Woodruffe, C. E. \& Goodpasture, E. W. (1929). The infectivity of isolated inclusion bodies of fowl-pox. Amer. J. Path. 5, 1.

\section{EXPLANATION OF PLATES}

All the micrographs are of infected chick chorio-allantoic membranes.

\section{Plate 9}

$4 \mathrm{hr}$. after inoculation with a large dose of vaccinia. Elementary bodies are seen indenting the surface in $(a)$ and beneath it in $(b)$. Both these micrographs are of sections cut at an oblique angle to the surface of the section, so that the structures illustrated appear further from the surface than they really were. $\times 56,000$. (c) Chorionic cell, $72 \mathrm{hr}$. after infection with ectromelia virus. A large immature virus body and a number of mature forms are seen. The immature body is surrounded by a thin membrane and contains an eccentric nucleus-like structure surrounded by an electron-transparent 'halo'. $\times 80,000$.

\section{Plate 10}

Chorio-allantoic membrane, $4 \mathrm{hr}$. after infection with vaccinia. Immature virus particles $(V)$ are embedded in a small area of fairly granular material which is surrounded by a ring of mitochondria $(M)$. Some of the immature forms present an incomplete outline, probably due to damage in preparing this specimen. The cell surface is seen in the upper left-hand corner. An electron-dense body of irregular outline is seen on the left. Such structures also occur in normal chorion cells. $\times 56,000$.

\section{Plate 11}

Vaccinia, $4 \mathrm{hr}$. after infection. A large area of amorphous material can be distinguished from the more granular cytoplasm; in it are immature virus bodies $(V)$, some showing incomplete outlines. Around it are mitochondria $(M)$. The cell surface is on the left. One immature form contains a nucleus-like body. A fold of the supporting membrane underlies part of the section. $\times 56,000$. 


\section{Plate 12}

$4 \mathrm{hr}$. after infection with vaccinia. Shows the finely granular structure of the material in which the immature forms $(V)$ are embedded. Part of the ring of mitochondria $(M)$ can be seen.

\section{Plate 13}

Vaccinia, $10 \mathrm{hr}$. after infection. The arrow indicates a mature virus body among a number of immature forms. Note the central nucleus-like structure, larger than those found in the immature forms, and the 'cortex' surrounding it. At this stage mitochondria, though still numerous, did not occur in such a distinctive ring. $\times 56,000$.

(MS. received for publication 15. II. 56) 

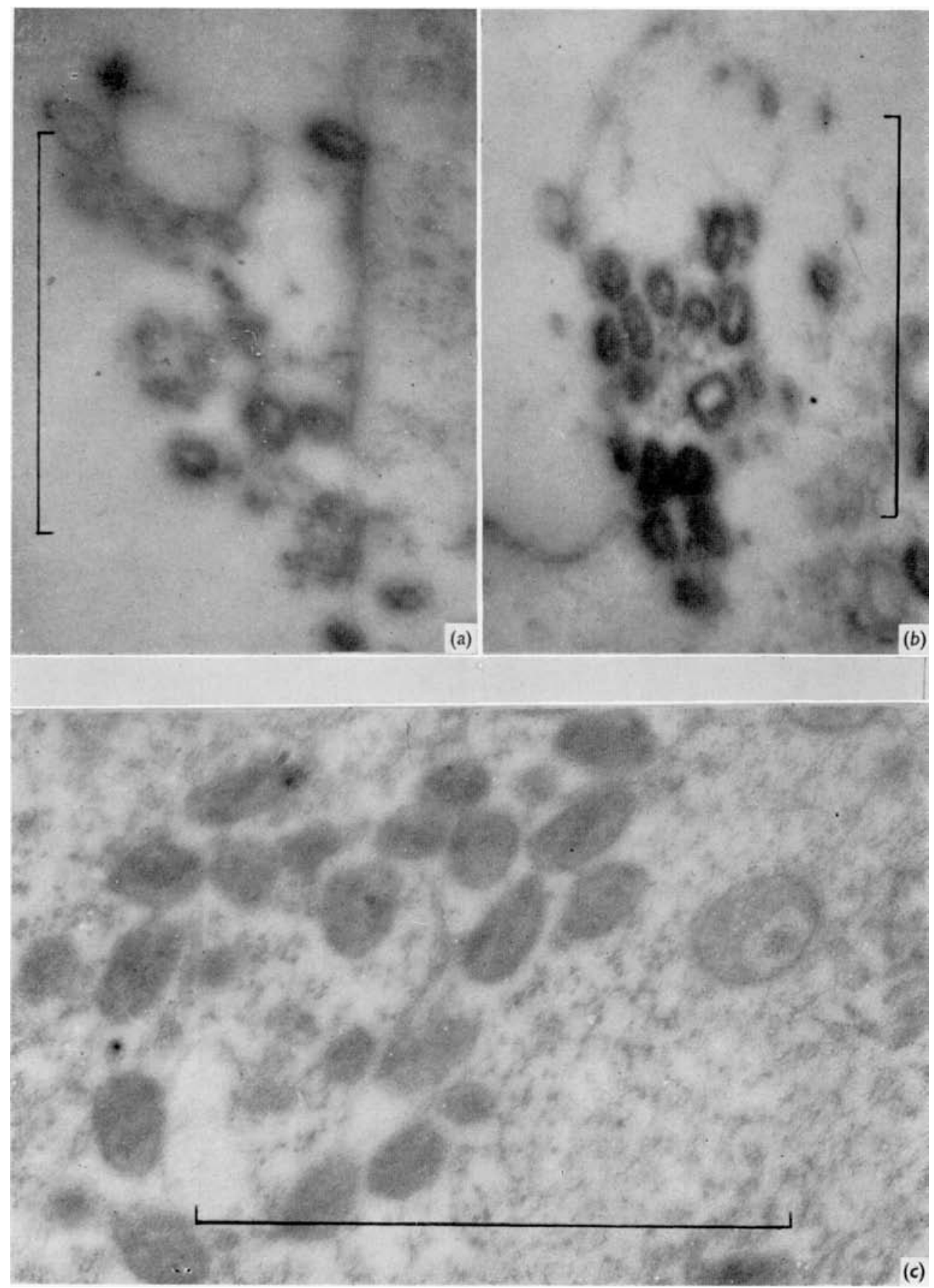
JOURNAL OF HYGIENE, VOL. 54, NO. 3

PLATE 10

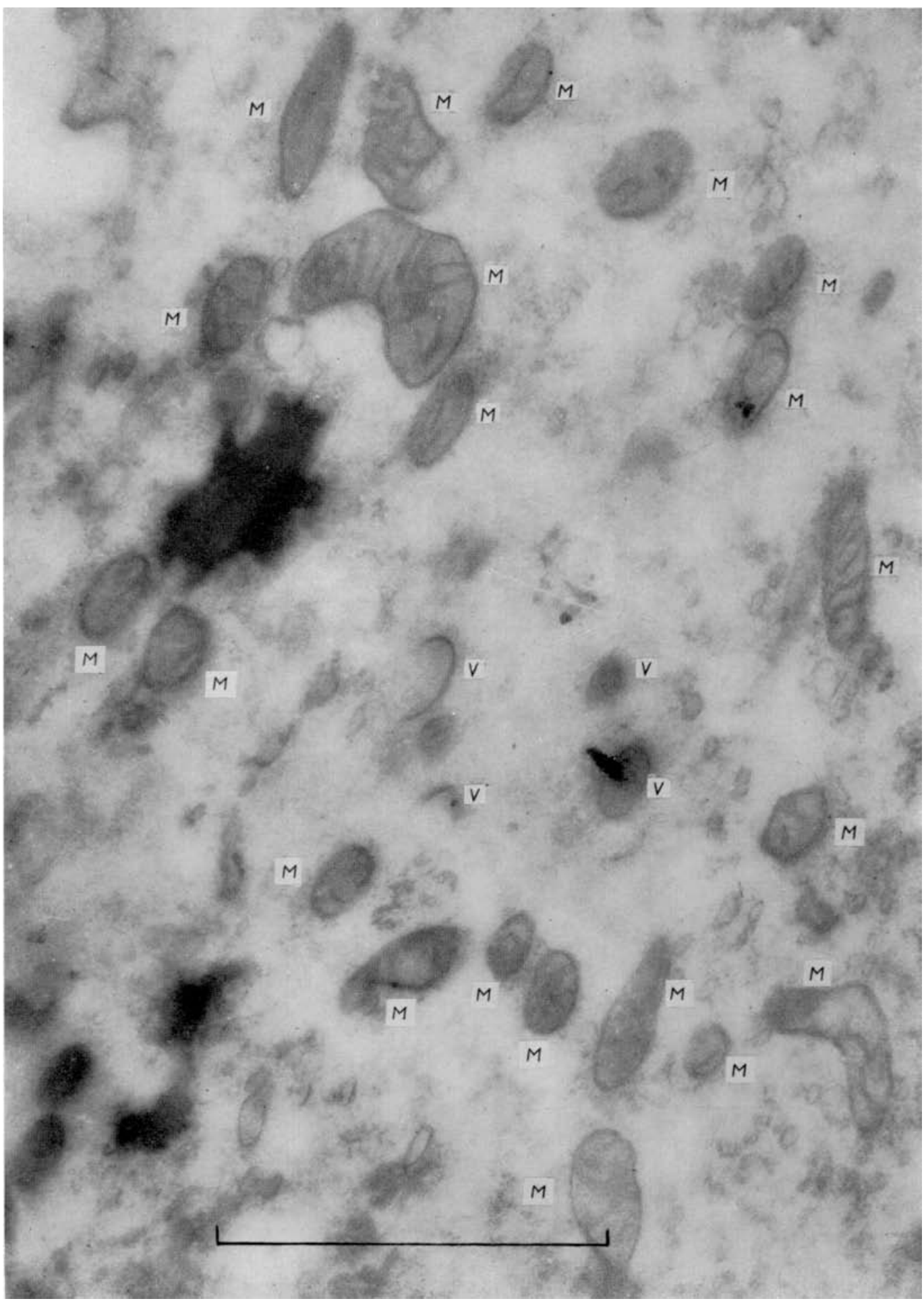


JOURNAL OF HYGIENE, VOL. 54, NO. 3

PLATE 11

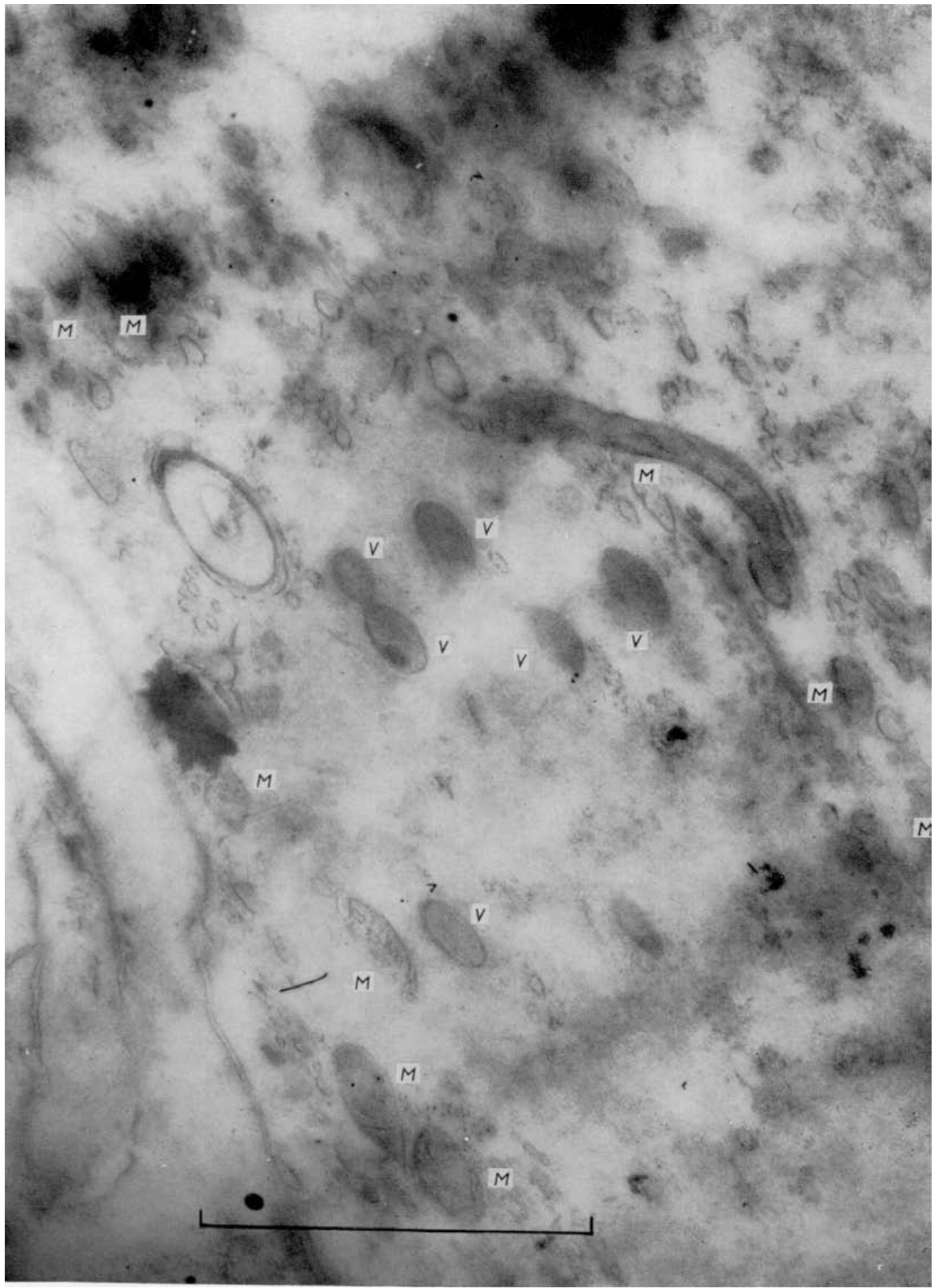




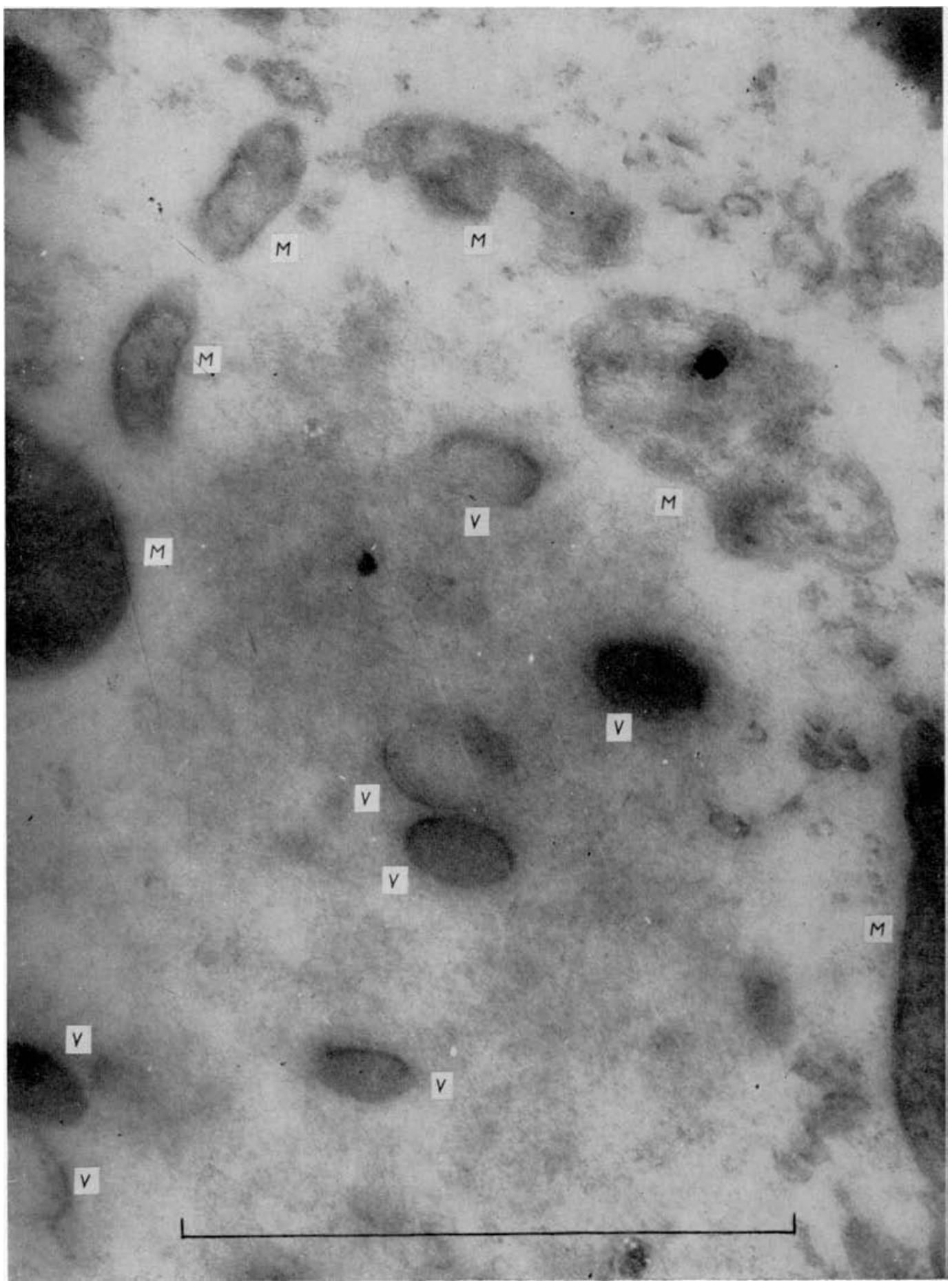




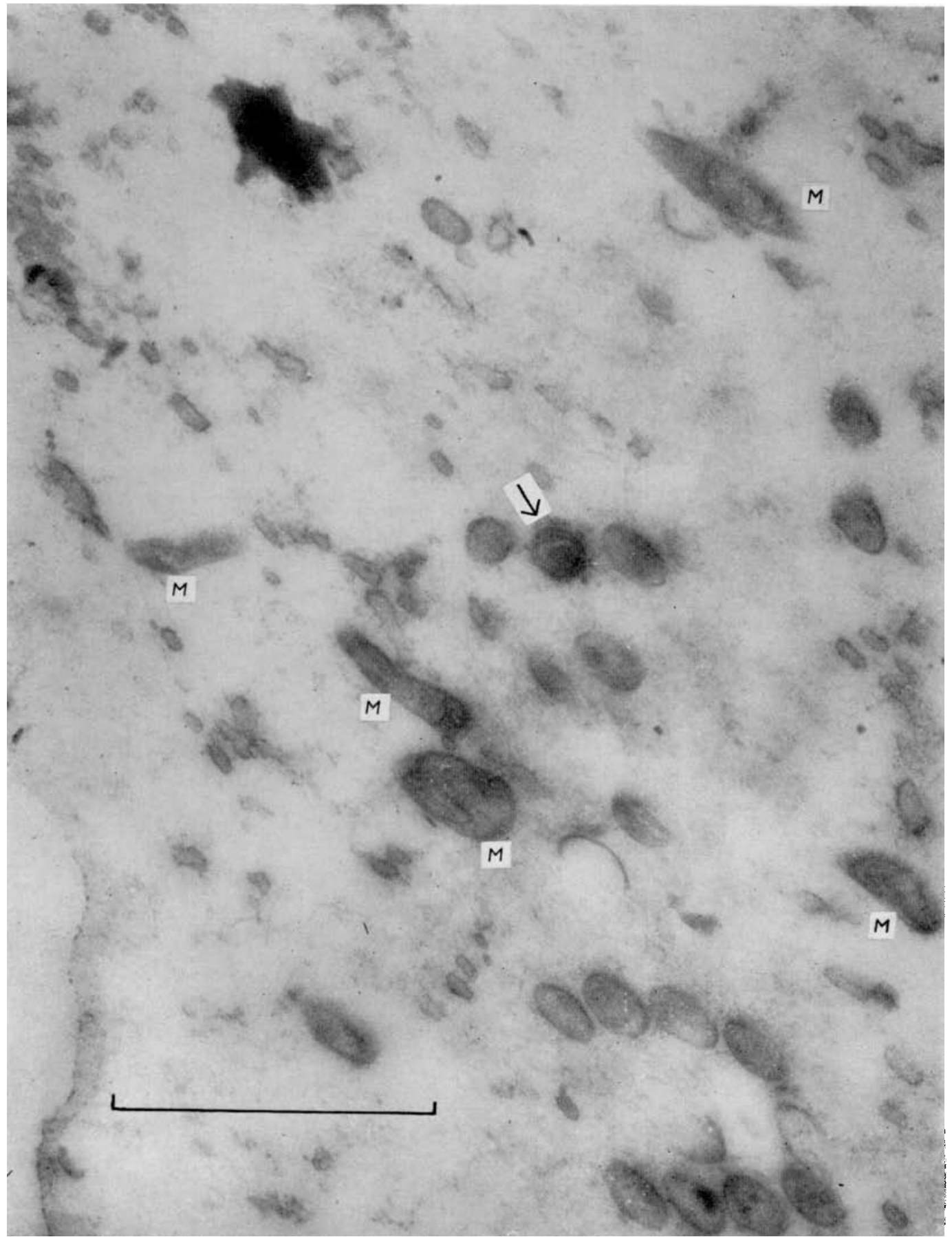

